\title{
RADIATION LABORATORY \\ UNIVERSITY OF NOTRE DAME
}

\section{QUARTERLY REPORT}

January 1, 1977 - March 31, 1977

$$
\begin{aligned}
& \text { This report was prepared as an account of work } \\
& \text { sponsored by the United States Government. Neither the } \\
& \text { United States nor the United States Department of } \\
& \text { Energy, nor any of their employees, nor any of their } \\
& \text { contractors, subcontractors, or their employees, makes } \\
& \text { any warranty, express or implied, or assumes any legal } \\
& \text { liability or responsibility for the accuracy, completeness } \\
& \text { or usefulness of any information, apparatus, product or } \\
& \text { process disclosed, or represents that its use would not } \\
& \text { infringe privately owned rights. }
\end{aligned}
$$




\section{DISCLAIMER}

This report was prepared as an account of work sponsored by an agency of the United States Government. Neither the United States Government nor any agency Thereof, nor any of their employees, makes any warranty, express or implied, or assumes any legal liability or responsibility for the accuracy, completeness, or usefulness of any information, apparatus, product, or process disclosed, or represents that its use would not infringe privately owned rights. Reference herein to any specific commercial product, process, or service by trade name, trademark, manufacturer, or otherwise does not necessarily constitute or imply its endorsement, recommendation, or favoring by the United States Government or any agency thereof. The views and opinions of authors expressed herein do not necessarily state or reflect those of the United States Government or any agency thereof. 


\section{DISCLAIMER}

Portions of this document may be illegible in electronic image products. Images are produced from the best available original document. 
The Notre Dame Radiation Laboratory is a facility of the U. S. Enerigy Research and Development Administration operated for ERDA by the University of Notre Dame under contract No. EY-76-02-0038. The majority of the programs within the Laboratory are supported by the Division of Physical Research of ERDA and unless otherwise noted in the following support can be attributed to the Division of Physical Research. Certain additional programs, so indicated, are supported by ERDA's Division of Biomedical and Environmental Research. The Radiation Chemistry Data Center, a center for radiation chemical information services operated by the Laboratory, is jointly sponsored by the Office of Standard Reference Data of the National Bureau of Standards and the Division of Physical Reesearch of the Energy Research and Development Administration.

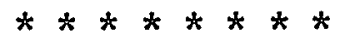

Dr. Franz Grieser (Ph.D. University of Melbourne, 1976) joined the staff on February 2. He is collaborating with Dr. Thomas on problems involving reactions in micellar systems.

Dr. Kunihiko Hasegawa (Ph.D. Tohoku University, 1972), Associate Professor at Shizuoaka University, Japan, wil1 spend the 1977-78 year with us while on leave from his University as Overseas Research Fellow. His interests lie in various areas of radiation chemistry.

Dr. W. O. Allen, recently retired from Brookhaven and currently Humboldt Fellow at the Hahn-Meitner Institute in Berlin, spent the week of February 6 with us as a visiting lecturer.

Dr. K. Iguchi, Professor of Chemistry at Waseda University, Japan, will spend a sabbatical period beginning in April at the Laboratory as Waseda University Scholar. 
Dr. E. V. Srisankar of the Saha Institute of Nuclear Physics has accepted an appointment as Research Associate and will join the Laboratory's staff in September.

Dr. B. Venkataraman, Professor and Director of Chemical Physics at the Tata Institute of Fundamental Research, Bombay, India, has accepted an appointment as Visiting Research Associate for one year beginning June $1 ; 1977$.

Dr. M. Almgren, Associate Professor at Chalmers Institute of Technology, Gothenburg, Sweden, will visit the Laboratory for the year beginning July 1, 1977 while on leave from his institution.

$$
\star * * * * * \star * \star
$$

During the quarter Drs. John Smalley (1-30-77), Hisatake Sano (3-477), Jon-Gil Lee (1-15-77), and Mrs.Gail Kedik (3-30-77) and Miss Debbie Stieglitz (1-31-77) have left the staff to accept positions elsewhere.

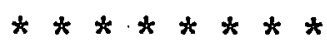

Jon-Gil Lee successfully defended his thesis "High-Field Conduction and Current Noise Implications of Mechanisms Contributing to Breakdown in Thin Films of $\mathrm{RbI}^{\prime \prime}$ and completed the requirements for the $\mathrm{Ph} . \mathrm{D}$. degree on December 10, 1976. His graduate studies were taken in the Department of Electrical Engineering under the direction of Professor William Berry with Professor William H. Hamill acting as an external advisor. Dr. Lee is currently working with Professor Hayes of the Chemistry Department. 
D. A. N. Morris defended his thesis "Dynamic Processes of Some Aromatic Molecules Solubilized in Phospholipid Micelles and Vesicles" and completed the requirements for the Ph.D. degree on March 10, 1977. His graduate studies were taken in the Department of Chemistry under the direction of Professor J. K. Thomas. Dr. Morris' graduate studies were supported by the Miles Laboratory and he has returned to full time responsibilities with Miles.

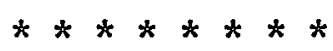

\section{Laboratory Facilities}

The $3 \mathrm{MeV}$ Van de Graaff accelerator transferred from CarnegieMellon has been reassembled in the newly constructed vault south of the Laboratory. Electron beams have been run at energies up to $3 \mathrm{MeV}$. The in situ-radiolysis-ESR experiment is currently being set up and it is expected that this experiment will become operational in the continuous mode during the third quarer of FY 17.

The Laboratory's new PDP $11 / 55$ computer system has been received and set up in Room 037. A RSX-11M executive operating system has been installed and transfer of programs and computational activities from the Univac 418 begun. Currently programing is being done in Fortran IV. Both the Fortran IV+ and Basic languages will be installed in the near future. This instrument provides multiuser capabilities and will be interfaced with the various Laboratory experiments that will benefit from computerized data acquisition. 
THIS PAGE

WAS INTENTIONALLY

LEFT BLANK 
Publications

James L. Fraites, John Bentley and Daniel H. Winicur

The determination of potential-well depths directly from rainbow maxima. J. Phys. B: Atom. Molec. Phys., 10, 127 (1977) [NDRL-1018]

Robert L. Bush and Koichi Funabashi

Small polaron model for the absorption spectrum of solvated electrons in alcohols.

J. Chem. Soc., Faraday Trans. II, 73, 274 (1977) [NDRL-1033]

F. Patricia Mullins and Columba Curran

Mossbauer studies of complexes of $\mathrm{SN}(\mathrm{NCS})_{4}$ and $\mathrm{SNI}_{4}$ with organic ligands. J. Inorg. Nuc1. Chem. 39, 377 (1977) [NDRI-1036]

J. L. Magee and W. P. Helman

Energy loss of electrons in random motion

J. Chem. Phys., 66, 310 (1977) [NDRL-1051]

William C. Troy and Richard J. Field

The amplification before decay of perturbations around stable states in a model of the Zhabotinskii reaction.

SIAM J. App1. Math., 32, 306 (1977) [NDRL-1605]

P. Neta, V. Madhavan, Haya Zemel, and Richard W. Fessenden

Rate constants and mechanism. of reaction of $\mathrm{SO}_{4}{ }^{-}$-with aromatic compounds.

J. Amer. Chem. Soc. , 99, 163 (1977) [NDRL-1655]

H. Sano and A. Mozumder

Model of thermalization of quasifree electrons in high-mobility liquids and it relationship with electron mobility.

J. Chem. Phys., 66, 689 (1977) [NDRL-1704]

A. 0 . Allen

Drift mobilities and conduction band energies of excess electrons in

dielectric liquids.

NSRDS-NBS 58,23 p. (1976) [SR-34]

A. 0 . Allen

Yields of free ions formed in liquids by radiation.

NSRDS-NBS 57, 25 p. (1976) [SR-35]

Radiation Chemistry Data Center

Thesaurus for radiation chemistry.

UND-RCDC-1 (March 1977) [SR-36]

Farhataziz and Alberta B. Ross

Selected specific rates of reactions of transients from water in

aqueous solution. III. Hydroxyl radical and perhydroxyl radical and

their radical ions.

NSRDS-NBS 59, (January 1977) [SR-38] 
The following reports were issued during the period of the quarter: I. (NDRL-998) A PULSED LASER STUDY OF EXCITED STATES OF AROMATIC MOLECULES ABSORBED IN GLOBULAR PROTEINS ${ }^{1 \dagger}$ (M. Cooper and J.K. Thomas)

ABSTRACT: Pyrene and several derivatives of pyrene such as pyrene sulphonic acid, and pyrene butyric acid were incorporated into Bovine Serum Albumin BSA, in aqueous solution. The pyrene chromophore was subsequently excited by a pulse of U.V. 1ight $\left(\dot{\lambda}=3471 A^{\circ}\right)$ from a $Q$ switched frequency doubled ruby laser. The lifetime of the pyrene excited singlet and triplet states were monitored by time resolved spectrophotometry. Various molecules, such as $\mathrm{O}_{2}$ and $\mathrm{I}^{-}$, dissolved in the aqueous phase, diffused into the protein and quenched pyrene excited states. The rates of these reactions were followed under a variety of conditions such as $\mathrm{pH}$ and temperature and in the presence of inert additives. The rates of pyrene excited state quenching were often considerably smallex than the rates observed in simple solutions. A comparison of the rates in the protein and homogeneous solutions gives information on the factors such as temperature, charge, and $\mathrm{pH}$, that control the movement of small molecules in and into BSA. .

(1) Submitted for publication in Radiation Research.

+ Supported by the Division of Biomedical and Environmental Research

II. (NDRL-1023) NONEQUILIBRIUM PHENOMENA IN THE KINETICS OF OZONE PRODUCTION IN THE STRATOSPHERE ${ }^{1}$ (John J. Kozak, Gregoire Nicolis, James W. Kress, Michèle Sanglier ${ }^{\dagger}$ )

ABSTRACT: In this paper we used the methods of nonequilibrium thermodynamics and non linear kinetics to analyze the chemical dynamics of ozone production in the stratosphere. To demonstrate the main features of the approach, we have restricted the chemical aspects of the problem to a consideration of the classical Chapman reaction sequence. However, mass and energy transfer between the reactive layer (in the stratosphere) and the inert layer (the troposphere) are considered explicitly, the calculations performed reveal a significant coupling between these transport processes and the chemical transformations taking place in the system. A linear. stability analysis of the atmospheric model developed in this paper, as well as representative numerical simulations, e.g., the determination of the temporal evolution of the concentrations of $0_{2}, 0 \cdot$ and $0_{3}$ and of the temperature for a variety of initial conditions and flows, allows a 
number of factors to be assessed: 1) the importance of considering the atmosphere as an open (as opposed to closed) thermodynamic system, operating away from equilibrium; 2) the stability of the mathematicallypossible, steady states of the system; 3) the new features brought in by regrading the atmosphere as having an evolving oxygen content, as well as the consequences of introducing various mechanisms for the destruction of $\mathrm{O}_{2}, 0 \cdot$ and $\mathrm{O}_{3}$ in the troposphere and stratosphere; and, 4) the interplay between the temperature of the ozonosphere and the concentrations of $\mathrm{O}_{2}$, 0 - and $\mathrm{O}_{3}$, and the attendant consequences of having markedly different time scales characterizing the chemical, mass transport and energy transport processes taking place in the system.

(1) Submitted for publication in the Journal of Atmospheric Science

+ Faculté de Sciences de l'Université libre de Bruxelles, Bruxelles. 1050, Be1gium

III. (NDRL-1727) ANALYTICAL EXPRESSION FOR ENERGY LOSS OF ELECTRONS IN RANDOM MOTION $^{1}$ (H. Sano)

ABSTRACT: The energy loss of a moving electron through the electromagnetic field in a dielectric medium is expressed in terms of the joint probability of finding the electron at two positions at two successive times. The resulting formula is applied to random-walk paths which are assumed to represent the motion of the subexcitation electron (energy range 1-6 eV or so)... The random-walk electron that wanders about loses more energy than the electron that moves away straight.

(1) Submitted for publication in the Journal of Chemical Physics

IV. (NDRL-1728) SOME ASPECTS OF ELECTRON TRANSPORT AND REACTIONS IN AQUEOUS MEDIA ${ }^{1}$ (A. Mozumder)

ABSTRACT: Irradiation produces in water and aqueous systems electrons in various states of trapping and solvation dependent upon time and temperature. In this talk a theoretical review will be attempted for the modes of motion of such electrons with reference to both earlier experiments and more recent findings. In particular criteria will be discussed on the basis of which diffusional, activational and longrange tunneling mechanisms may be distinguished as modes of chemical reactions with solutes. The discussion will be developed in two stages with a certain amount of overlap between them. In the first stage will 
be described diffusional and non-diffusional transport and reactions of mainly solvated electrons in the liquid phase. Effect of temperature and activation energy of reaction will be treated according to alternative theories... Influence and importance of short-range tunneling in liquidphase reactions will be delineated. In partlally diffusion-controlled reactions effect of multiple encounter will be described according to the Noyes model and a recent formulation of the author. The second state of the discussion will be devoted exclusively to certain theoretical aspects of trapped and solvated electron reactions in low-temperature rigid aqueous glassy systems. Special reference will be made to long-range electron tunnelling. Time and solute-concentration dependence of electron-density profiles will be derived on a simple model.

(1) Submitted for presentation at the Americal Physical Society, Division of Biological Physics Symposia, San Diego, California, March 21-24 (1977)

V. $\quad($ NDRL-1730) REACTION OF TYPE II BIRADICALS WITH PARAQUAT IONS. MEASUREMENT OF BIRADICAL LIFETIMES (Richard D. Smal1 and Juan C. Scaiano)

ABSTRACT: A laser photolysis study of the Norrish Type II reaction of $\gamma$-methylvaleropnenone in the presence of paraquat ions has allowed us to measure for the first time the lifetime of a Type II biradical and the rate constant for the intermolecular reaction-with paraquat ions. Iil methanol at room temperature $\tau_{B}=(97 \pm 15)$ ns and $\underline{k}_{T}=(4.6 \pm 0.6) \times$ $10^{9} \underline{M}^{-1} s^{-1}$. The value of the lifetime is considerably shorter than values estimated previously from competitive studies.

A fraction of the paraquat radical ions generated in the trapping step decay via reaction with the radical $\mathrm{PhCOCH}_{2} \mathrm{CH}_{2} \dot{\mathrm{CMe}}_{2}$.

(1) Submitted for publication in the Journal of Physical Chemistry

VI. (NDRL-1731) DETERMINATION OF THE PAIR POLARIZABILITY TENSOR FOR THE NE DIATOM ${ }^{1}$. (James W. Kress and John J. Kozak)

ABSTRACT: The pair polarizability tensor A for the-neon diatom, $\mathrm{Ne}_{2}$, has been determined as a function of the $\mathrm{Ne}-\mathrm{Ne}$ 'separation using an extended gaussian basis set and the finite perturbation coupled. HartreeFock technique. Our results are compared with calculations reported 
previously on the Ne diatom (the earlier calculations were based on a density functional approach), and are found to differ significantly in the estimate of the anisotropy in the tensor $A$.

(1) Submitted for publication in the Journal of Chemical Physics

VII. (NDRL-1732) THE STRUCTURE AND STATE OF $\mathrm{H}_{2} \frac{\mathrm{O}}{+}$ IN REVERSED MICELLES (III) $^{1}$ (M. Wong, J.K. Thomas and T. Nowak ${ }^{\dagger}$ )

ABSTRACT: The structure and state of water in the reversed micellar system, Na-diisoocty 1 sulfosuccinate $/ \mathrm{H}_{2} \mathrm{O} /$ heptane was investigated by both ${ }^{1} \mathrm{H}$ and ${ }^{23} \mathrm{Na}$ NMR spectroscopy. The ${ }^{1} \mathrm{H}$ NMR spectrum of $\mathrm{H}_{2} \mathrm{O}$ exhibits a downfield chemical shift with increasing water content of the system, gradually approaching that of ordinary water. This suggests a minimal amount of hydrogen bonding present in the micellar water phase. With increasing water content of this system, both. the spin-lattice relaxation rates $\left(1 / \mathrm{T}_{1}\right)$ and spin-spin relaxation rates $\left(1 / \mathrm{T}_{2}\right)$ of ${ }^{1_{H}}$ of water decrease significantly up to $1 \% \cdot \mathrm{H}_{2} \mathrm{O}$, and then decrease much slowly with further addition of water. A simple calculation of the rotational correlation time $\tau_{c}$ from $T_{1}$ demonstrates that the water molecules are highly immobilized in small water pools due to strong ion-dipole interaction with counter ions. On completion of the solvation shell of the counter ion (i.e. $1 \%$ $\mathrm{H}_{2} \mathrm{O}$ or $\mathrm{H}_{2} \mathrm{O} / \mathrm{Na}^{+} \cong 6$ ), the rigidity of the micellar core is greatly reduced. ${ }^{23} \mathrm{Na}$ NMR measurements.. show an analogous decrease in the $1 / \mathrm{T}_{2}$ with increasing $\mathrm{H}_{2} \mathrm{O}$ content. In the largest water pool, viz. $6 \% \mathrm{H}_{2} \mathrm{O}$, it is estimated that an upper limit of $28 \%$ of the $\mathrm{Na}^{+}$is dissociated from the sulfosuccinate head group.

The electronic absorption spectrum of iodide ion in the above systems is quite different from that in bulk water. The intensity of the spectrum increases with increasing water content. These data are also interpreted in terms of a decreased rigidity and increased hydrogen bonding of the micellar water pool with increasing water content.

(1) Submitted for publication in the Journal of the American Chemical Society

+ Department of Chemistry, University of Notre Dame, Notre Dame, Indiana 46556 
VIII. (NDRL-1733) VERY LOW TEMPERATURE PULSE RADIOLYSIS: PROTIATED AND PERDEUTERATED METHANOL GLASSES AT 6K ${ }^{1}$ (Lewis M. Perkey and John F. Smalley)

ABSTRACT: Spectra resulting from the pulse radiolysis of glasses of both $\mathrm{CH}_{3} \mathrm{OH}$ and $\mathrm{CD}_{3} \mathrm{OD}$ at $6 \mathrm{~K}$ were observed. Immediately after the end of the electron pulse, the absorption maxima of these spectra (625 nm for $\mathrm{CH}_{3} \mathrm{OH}$ and $720 \mathrm{~nm}$ for $\mathrm{CD}_{3} \mathrm{OD}$ ) are only slightly red-shifted from the absorption maximum obtained when these alcohols are gamma irradiated at $4.2 \mathrm{~K}$ (i.e. $600 \mathrm{~nm}$ ). Bleaching studies indicate that these gamma radiolysis spectra are composed of a visible portion which is due to solvated electrons and a near infrared portion which is due to trapped electrons. The near infrared portion of the pulse radiolysis spectra at $6 \mathrm{~K}$ are enhanced compared to the above gamma radiolysis spectra, and they decay to the latter spectra by a first order process. The effect of benzyl chloride upon these pulse radiolysis spectra leads to the conclusion that the transient near infrared absorption resulting from the pulse radiolysis of methanol at $6 \mathrm{~K}$ is due to an electron trapped geminate to. its parent cation. Additionally, since these pulse radiolysis spectra at $6 \mathrm{~K}$ are fully developed immediately after the electron pulse, it is concluded that, in vitreous methanol, electrons are localized in pre-existing potential wells which may be either deep or shallow. A discussion of the effect of alcohol deuteration upon the spectra and kinetics observed - in this work is also presented.

(1) Submitted for publication in the Journal of Physical Chemistry

IX. (NDRL-1734) METHODS FOR THE CALCULATION OF PHOTOIONIZATION CROSS-SECTIONS USING THE EXTENDED KOOPMANS' THEOREM ${ }^{1}$ (Danie1 M. Chipman)

ABSTRACT: A new approach to the calculation of photoionization cross sections for atoms and molecules is described. The procedure requires for input only a wave function for the parent initial state, obviating the necessity of a separate calculation on the, final bound state by making use of the recently developed Extended Koopmans' Theorem. Explicit formulae for the photoionization cross sections, in terms of the one and two particle reduced density matrices of the initial state wave function, have been obtained at several levels of sophistication; 
including the sudden approximation, an orbital model for the photoelectron, and a close-coupling model. In the latter two cases, equations have been derived for the optimization of the continuum orbitals required for the description of the outgoing photoelectron. Approximations which make the optimization equations more tractable are also discussed.

(1) Presented at the International" Symposium on Atomic, Molecular and Solid-State Theory, Collision Phenomina and Computational Methods, Sanibel Island, Florida, January 16-22, 1977. Submitted for publication in the International Journal of Quantum Chemistry Symposium Issue

X. (NDRL-1735) THEORY OF RESONANT RAMAN SCATTERING IN THE STRONG VIBRONIC COUPLING LIMTT - A GREEN'S FUNCTION APPROACH ${ }^{1}$

(Hwei-kwan Hong)

ABSTRACT: A Green's function approach for resonant Raman scattering is propoesd here, which is suitable for both weak and strong vibronic couplings. The formalism is based on the solution of the exact Green's function in the LonguetHiggins representation, using the static equations in ordinary molecular quantum mechanics as the basis set. The physical meaning of various interaction schemes becomes clear in this representation. In particular, the vibronic coupling is based on the interactions between individual zeroorder vibronic levels and carrys through the infinite orders rather than the traditional first order results which account only for the emission or the absorption of one single vibrational quantum. Nonadiabatic contributions are also contained in the formulation. The method is applied to the following cases: (1) the change in nuclear equilibrium position due to electronic excitation; and (2) vibronic coupling involving two excited states (3) the change in nuclear potential (force constants) due to electronic excitation. Numerical results show that the convergence is excellent even for large vibronic coupling and in exact resonance region. Furthermore, all the physical quantities of interest, such as Raman cross sections of fundamentals and overtones, absorption profiles, Franck Condon factors, quantum yields can be obtained at the same time in this unified approach.

(1) Submitted for publication in the Journal of Chemical Physics 
XI. (NDRL-1736) CONTINUOUS-RANDOM-WALK IN THREE DIMENSIONS AS A MODEL FOR ELECTRON SCAVENGING AND ION RECOMBINATION IN LIQUIDS

(W.P. Helman and K. Funabashi)

ABSTRACT: Time-dependent rates of electron scavenging reactions were calculated using the model of continuous-time-random-walk (CTRW) of Montroll and Weiss for the hopping time distribution functions of an exponential form and a few non-exponential forms. The result was applied to the charge neutralization reaction using the Laplace transform technique. It was found that the rate constant in the CTRW model is smaller than the Smoluchowski transient rate, but is larger than the time-independent (asymptotic) value at the time scale which is comparable or shorter than the average jump time. The differences in the decay pattern and the survival fraction of electrons between the CTRW model and the Smoluchowsi treatment are much less than those in the rate constants themselves.

(1) Submitted for publication in the Journal of Chemical Physics

XII. (NDRL-1737) ELECTRON TRANSFER, EQUILIBRIUM, AND PROTONATION IN THE SYSTEM OF CIS- AND TRANS-STILBENE IN 2-PROPANOL ${ }^{1}$ (Haim Levanon and P. Neta)

ABSTRACT: Spectrophotometric pulse radiolysis experiments with cis- and trans-stilbene $\left(S_{c}\right.$ and $S_{t}$ ) in 2-propanol show that both isomers react with the solvated electron with a rate constant of $4.5 \times 10^{9} \mathrm{M}^{-1} \mathrm{~s}^{-1}$. The absorption spectra of the two anion radicals have maxima at 496 and $486 \mathrm{~nm}$, respectively. The absorbances at 400-550 nm disappear exponentially corresponding to a pseudo first order protonation of the anion radicals. The rate constants for the protonation of the cis isomer is $6.4 \times 10^{5}$ and of the trans isomer $0.7 \times 10^{5} \mathrm{~s}^{-1}$. In mixtures of cis- and transstilbene the electron transfer $\mathrm{S}_{\mathrm{c}}^{--}+\mathrm{S}_{\mathrm{t}} \underset{\mathrm{s}}{\mathrm{c}}+\mathrm{S}_{\mathrm{t}}^{--}$has a forward rate constant of $9 \times 10^{7} \mathrm{M}^{-1} \mathrm{~s}^{-1}$ while the back reactions has a rate constant of $2.15 \times 10^{7} \mathrm{M}^{-1} \mathrm{~s}^{-1}$. An equilibrium constant $\mathrm{K}=4.2$ is calculated.

(1) Submitted for publication in Chemical Physics Letters 
XIII. (NDRL-1738) CHEMICALLY INDUCED ELECTRON POLARIZATION OF RADIOLYTICALLY PRODUCED RADICALS ${ }^{1}$ (Richard W. Fessenden)

ABSTRACT: The stucy of chemically incuded electron polarization of radicals produced by the radiolysis of aqueous solutions is described. The experimental arrangement necessary for pulse ESR experiments with submicrosecond time resolution is discussed. Direct detection of the ESR signal with no field modulation is preferred so that quantitative analysis is possible. The effect of the radiolysis pulse on the spectrometer is described. A brief review of the radiolytic formation of primary radicals in spurs is given to show that considerable reaction of the radicals occurs before complete separation of the pairs. Analysis of the observed time profiles of the ESR signals is by means of Bloch equations so modified to include both initial polarization and polarization by spin selective reaction. Data from direct observation of the hydrated electron and $\mathrm{H}$ atoms are given along with indirect data obtained by study of products of their reaction. Data for the products of oH reaction are also given. In each case it appears that the spin populations of the primary radicals can be transferred to the product. It can be concluded that $\mathrm{e}_{\mathrm{aq}}^{-}$initially has equal populations of the two spin states to within 0.2 of the Boltzmann value while OH appears to be relaxed to equilibrium in less than $1 \mathrm{nsec}$. Primary $\mathrm{H}$ atoms show a significant initial effect probably as a result of reactions before escape from the spur. Several unresolved aspects of the observations are also discussed.

(1) Presented at the NATO Advanced Study Institute on Chemically Induced Magnetic Polarization to be held April 17-30 in Urbino, Italy. To be published in the proceedings of the Institute.

XIV. (NDRL-1739) PHOTOREACTIONS OF $\left[\left(n^{5}-\mathrm{C}_{5} \mathrm{H}_{5}\right) \mathrm{Fe}(\mathrm{CO})_{2}\right]_{2}$ WITH POTENTIAL HYDROGEN DONORS ${ }^{1}$ (J.A. Labinger and S. Madhavan) ABSTRACT: Photolysis of the metal-metal bonded dimer $\left[\left(n^{5}-\mathrm{C}_{5} \mathrm{H}_{5}\right) \mathrm{Fe}(\mathrm{CO})_{2}\right]_{2}$. in the presence of a variety of potential hydrogen atom donors leads to net. hydrogen abstraction only in the case of benzaldehyde, for which $\left(n^{5}-\mathrm{C}_{5} \mathrm{H}_{5}\right) \mathrm{Fe}(\mathrm{CO})_{2}\left(\mathrm{C}_{6} \mathrm{H}_{5}\right)$ is the only product formed. Photolysis in acetonitrile gives the monosubstitution product $\left(n^{5}-\mathrm{C}_{5} \mathrm{H}_{5}\right)_{2} \mathrm{Fe}_{2}(\mathrm{CO})_{3}\left(\mathrm{CH}_{3} \mathrm{CN}\right)$.

(1) To be published in the Journal of Organometallic Chemistry 
XV. (NDRL-1740) INTERACTION OF OXYGEN WITH TRANS IENT BIRADICALS PHOTOGENERATED EROM Y-METHYL VALEROPHENONE ${ }^{1}$ (Richard D. Sma11, Jr. and Juan C. Scaiano)

ABSTRACT: The 1,4-biradicals generated during the photolysis of $\gamma$ methyl valerophenone interact with oxygen at nearly diffusion controlled rates. The comparison of quantum yield studies in benzene with laser photolysis experiments in methanol allow the estimation of the biradical lifetime in benzene as 42 ns at room temperature.

(1) To be published in Chemical Physics Letters

XVI. (NDRL-1741) REACTIONS OF PHOSPHATE RADICALS WITH ORGANIC COMPOUNDS ${ }^{1}$

(P. Maruthamuthu and P. Neta)

ABSTRACT: Phosphate radicals in the three acid-base forms, $\mathrm{H}_{2} \mathrm{PO}_{4}$, $\mathrm{HPO}_{4}^{-}$, and $\mathrm{PO}_{4}^{2-}$, were produced by the reaction of hydrated electrons with peroxodiphosphate ions at $\mathrm{pH}$ values of $3-4,7-9$, and 12 respectively. Rate constants for the reactions of these radicals with organic compounds were determined by following the rate of decay of the phosphate radical absorption in the presence of increasing concentrations of the substrate. Rates of reaction of $\mathrm{H}_{2} \mathrm{PO}_{4}$ were found to be higher than those of $\mathrm{HPO}_{4}$ and $\mathrm{PO}_{4}^{2-}$ by a factor of $44-10$, while the latter radicals have similar rates. The rate constants for hydrogen abstraction from aliphatic compounds ranged from $\sim 10^{5} \mathrm{M}^{-1} \mathrm{~s}^{-1}$ for acetic acid and t-butanol to $\sim 10^{8} \mathrm{M}^{-1} \mathrm{~s}^{-1}$ for 2-propanol and formate. Addition to a double bond was not faster but reaction with aromatic compounds reached a rate constant $>10^{9} \mathrm{M}^{-1} \mathrm{~s}^{-1}$ for the most reactive compounds. The effects of substituents were found to be similar for $\mathrm{H}_{2} \dot{\mathrm{PO}}_{4}$ and $\mathrm{SO}_{4}^{-}$and both radicals are suggested to react with the aromatic ring by one-electron transfer to the inorganic radical. In hydrogen abstraction reactions $\mathrm{H}_{2} \mathrm{PO}_{4}$ (and $\dot{\mathrm{SO}}_{4}^{-}$) were found to react with rate constants $210-100$ times lower than those of $\mathrm{OH}$ and to have a selectivity about three times higher than that of $\mathrm{OH}$. Radiolytic chain decomposition of peroxodiphosphate in the presence of some organic compounds" was also studied.

(1) Submitted for publication in the Journal of Physical Chemistry 
XVII. (NDRL-1742) PHOTOCHEMISTRY OF PHENYL ALKYL KETONES IN THE PRESENCE OF ORGANOPHOSPHOROUS (V) COMPOUNDS ${ }^{1}$ (Juan C. Scaiano)

- ABSTRACT: Triphenylphosphine-oxide, as well as organic phosphates $\left[(\mathrm{MeO})_{3} \mathrm{PO},(\mathrm{PrO})_{3} \mathrm{PO}\right.$ and $(\mathrm{PhO})_{3} \mathrm{PO}$ ] interact with the biradicals produced in the photochemistry of phenyl alkyl ketones (e.g. valerophenone) increasing the yields of photofragmentation and cyclization. The effect is presumed to result from the formation of a complex between the organophosphorus substrate and the intermediate biradical.

(1) Submitted for publication in the Journal of Organic Chemistry

XVIII. (NDRL-1.744) LASER PHOTOLYSIS STUDY OF BIRADICAL REACTIONS ${ }^{1}$

(R.D. Sma11 and J.C. Scaiano)

ABSTRACT: The biradicals generated in the photolysis of alkyl aryl ketones react with paraquat ions. $\left(1,1^{\prime}\right.$-dimethy $1-4,4^{\prime}$ bipyridylium, $\mathrm{PQ}^{++}$) generating the stable paraquat radical-ion, $\mathrm{PQ}^{+\cdot}$.<smiles>CC(C)CCC(=O)c1ccccc1</smiles><smiles>[Te]C1CC1</smiles><smiles>CC(C)(C)CCC(O)c1ccccc1</smiles><smiles>CC(C)(C)CCC(O)c1ccccc1</smiles>

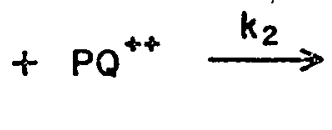<smiles>CC(C)(C)CCC(=O)c1ccccc1</smiles><smiles>CC(C)(C)CCC(=O)c1ccccc1</smiles><smiles>[Y3]C1CC1</smiles>

unimolecular decay

By analyzing the time profile for the formation of $\mathrm{PQ}^{+\cdot}$ using nanosecond laser photolysis it has been possible to determine the values of $k_{2}$ and $k_{3}\left(k_{3}=\tau_{B}^{-1}\right)$.

All the previous estimations of biradical lifetimes are based on chemical competition studies, requiring the assumption of a rate constant for the tapping reaction. This is the first report on direct time resolved measurements of biradical lifetimes. The results show that 
Type II biradicals are shorter lived than suggested by competion studies. The effects of oxygen, temperature, substitution and solvent on the biradical lifetimes have also been examined.

(1) Submitted for presentation at the Second International Symposium on Organic Free Radicals, Aix-en-Provence, France, July 16-23, 1977

XIX. (NDRL-1745) ELECTRON SCAVENGING IN ETHANOL AND IN WATER ${ }^{1}$ (Dusan Razem and William H. Hamil1)

ABSTRACT: Rate constants for scavenging solvated electrons, $e_{s}^{-}$, mostly in the range $\mathrm{k}_{\mathrm{e}}^{-}<10^{8} \mathrm{M}^{-1} \mathrm{~s}^{-1}$, have been measured in ethanol and, as needed for comparison, in water. There is a tendency for $\mathrm{k}_{\mathrm{e}}^{-}$to equal $\mathrm{k}_{\mathrm{e}}^{-}$over a $10^{3}$-fold range, but there are instances where $\mathrm{k}_{e^{-}}$is much greater. Inefficient scavengers for $e_{s}^{-}$provide relatively efficient traps for dry electrons $\mathrm{e}^{-}$with $37 \%$ survival often at $\underline{\mathrm{C}}_{37} \cong 1$ M scavenger but a1so as low as $\sim 0.2 \mathrm{M}$. The outstanding exceptions are olefins for which $\mathrm{k}_{\mathrm{e}^{-}} \simeq 3 \times 10^{7} \mathrm{M}^{-1} \mathrm{~s}^{-1}$, but they do not measurably react with $\mathrm{e}^{-}$. Negative $\mathrm{s}$ ion resonances for alkenes as large as $2.2 \mathrm{eV}$ have been reported and neither $\mathrm{e}^{-}$nor $\mathrm{e}_{\mathrm{s}}^{-}$is expected to react. It is proposed that $\mathrm{e}_{\underline{\mathrm{s}}}^{-}$is $\mathrm{C}_{2} \mathrm{H}_{5} \mathrm{OH}^{-}$and $\mathrm{e}_{\text {aq }}^{-}$is $\mathrm{H}_{2} \mathrm{O}^{-}$. The radical anions may transfer either $e^{-}$or $\mathrm{H}$ to appropriate acceptors, the latter accounting for reaction of $\mathrm{e}_{\mathrm{s}}^{-}$with olefins. The reaction $\mathrm{e}_{\mathrm{aq}}^{-}+\mathrm{e}_{\mathrm{aq}}^{-}=\mathrm{H}_{2}$ is explained in terms of $\mathrm{H}_{2} \mathrm{O}^{-}$. Whenever $e^{-}$and $e_{s}^{-}$produce a common electron adduct $\mathrm{s}^{-}$; and an equilibrium $\mathrm{e}_{\mathrm{s}}^{-}+\mathrm{s} \rightleftharpoons \mathrm{s}^{-}$is approximated, then $\underline{\mathrm{c}}_{-37}^{-1}$ is proportional to $\mathrm{k}_{\mathrm{e}}^{-}$. This is Hunt's relation, $\mathrm{k}_{\mathrm{e}}-\mathrm{C}_{37}=\mathrm{Q}$, with $\mathrm{Q}=1.2 \times 10^{9} \mathrm{~s}^{-1}$ in ethanol. Combining this with $\underline{\mathrm{k}}_{\mathrm{e}}-\underline{\mathrm{C}}_{37} \mathrm{~S}^{\mathrm{S}}=1$, with $\tau$ the lifetime in the delocalized state, it can be estimated that $\tau$ is $\sim 7 \times 10^{-13} \mathrm{~s}$ in ethanol. For $Q=$ $1.0 \times 10^{10}$ in water $\tau$ is $\sim 7 \times 10^{-14} \mathrm{~s}$.

(1) Submitted for publication in the Journal of Physical Chemistry

XX. (NDRL-1746) REACTION OF OH RADICAL WITH NAPHTHALENE ${ }^{1}$ (V. Madhavan) ABSTRACT: Hydroxyl radicals react with naphthalene in aqueous solution in the presence of $\mathrm{K}_{3} \mathrm{Fe}(\mathrm{CN})_{6}$ to yield 1- and 2-naphthol, respectively, in the ratios of $2.1: 1.0$. The reagent radicals were formed by gamma radiolysis and the product naphthols were analyzed by high performance liquid chromatography. Presumably, two isomeric benzo-hydroxycyclo- 
hexadienyl radicals are formed, which, on oxidation by $\mathrm{K}_{3} \mathrm{Fe}(\mathrm{CN})_{6}$ yield the two naphthols. The preferential formation of 1-naphthol indicates that $\dot{O} H$ behaves as an electrophile and seeks the 1-position of naphthalene which has a somewhat higher electron density than does the 2-position. The two naphthols account for at least $93 \%$ of the reaction of $\dot{0}$ at low conversion so that very little $\mathrm{OH}$ attack can occur at the 9-position of naphthalene.

(1) Submitted for publication in the Journal of Physical Chemistry

XXI. (NDRL-1747) PHOTO-IONIZATION AND TRAPPING OF ELECTRONS BY WATER BUBBLES IN HEPTANE ${ }^{1}$ (M. Wong and J.K. Thomas)

ABSTRACT: Water bubbles of various sizes and of known composition are produced in liquid heptane by the surfactant Aerosol OT. Electrons are generated in this system either by pulse radiolysis of by laser photoionization of various pyrene derivatives. In pulse radiolysis the electrons are initially generated in the hydrocarbon phase but are rapidly captured by the water bubbles. The rate of capture varies approximately with the square of the water bubble radius. Pyrene and various pyrene derivatives, such as pyrene sulfonic acid PSA, pyrene butyric acid, PBA, pyrene dodecanojc acid PDA, and amino-pyrene AP, on laser photolysj.s produce electrons which are captured by the water bubble. In each case the electron is produced in a different position with respect to the water bubble, e.g. with PSA it is produced in the bubble, with AP at the edge of the bubble and with PBA and PDA at different distances from the bubble in the heptane. The kinetic behavior of the electron in each case is different and will be discussed. The photolysis of AP is one photon at $3471 \AA$ which is $3 \mathrm{eV}$ below the gas phase IP. This have interest for solar energy storage.

(1) Submitted for presentation at the American Chemical Society Meeting, New Orleans, La., March 20-23, 1977.

XXII. (NDRL-1748) FLUORESCENCE PROBE STUDIES ON MICELLAR STRUCTURE ${ }^{1}$

(K. Kalyansandaram and J.K. Thomas)

ABSTRACT: The solvent-dependence of monomer fluorescence in pyrene and pyrene-3-aldehyde have been used as probes to study properties of micellar aggregates such as critical micelle concentration, extent of 
water penetration and to estimate the polarity at micelle-water interfaces. The intensities of the vibronic fine structure in pyrene monomer fluorescence show strong solvent dependence. In the presence of polar solvents, there is and enhancement of the $0-0$ band at the expense of other bands. Based on detailed studies in some thirty different solvents, a correlation between the enhancement of $0-0$ band (peak I) intensity relative to $0-737 \mathrm{~cm}^{-1}$ band (peak III) with solvent polarity is established. This strong perturbation of vibronic band intensities has been used as a probe to accurately determine CMC of various surfactants as well as the extent of water penetration in micellar solutions. . The monomer fluorescnece of pyrene-3-aldehyde also shows a strong dependence on solvent polarity. The fluorescence in non-polar solvents is very weak but is quite intense in polar solvents. The fluorescence maximum shows a red shift with increased solvent polarity which is linear with solvent dielectric constant. This strong dependence of fluorescence maxima and yield on solvent polarity has been used to obtain estimates on polarity at micelle-water interfaces for various ionic and nonionic micelles. The measured values are in excellent agreement with the zeta potentials of micellar stern layer and similar estimates using other fluorescence probes.

(1) Submitted for presentation at the American Chemical Society meeting, New Orleans, La., March 20-23, 1977

XXIIT. (NDRL-1.749) RESONANCE RAMAN AND FLUORESCENCE STUDIES OF FREE RADICALS: $\alpha$-HYDRONAPHTHYL RADICAL IN THE IRRADTATED NAPHTHALENE CRYSTAL ${ }^{1}$

(Clayton W. Jacobesn, Hwei-Kwan Hong and S.J. Sheng)

ABSTRACT: The vibrational structure of the fluorescence from the $\alpha$-hydronaphthyl radical produced by ionization radiation of naphthalene crystals is analyzed. The resonance Raman scattering of the radical is observed through an enhancement factor of $10^{5}$.

(1) Submitted for publication in Chemical Physics Letters

XXIV. (NDRL-1750) THEORY OF RESONANT RAMAN SCATTERING II. OVERTONES AND HOT BANDS (Hwei-kwan Hong)

ABSTRACT: Resonant Raman scattering is discussed in the framework of the Green's function method in both the strong and weak vibronic coupling limits. We further elaborate on the meaning of each matrix 
element of the Green's function, evaluated in the convenient basis set which is commonly referred to as the Longuet-Higgins representation. Cross sections for absorption, Rayleigh, Raman fundamentals, Raman overtones, hot bands, etc. can all. be related to the matrix elements of the Green's function. It is further emphasized that only in the vibronic view elaborated here does a simple and direct correlation exist between the light scattering processes and the Green's functions. Some typical excitation profiles for overtones and hot bands are calculated and the consequences of strong vibronic couplings are discussed in contrast to the weak vibronic coupling case.

(1) Submitted for publication in the Journal of Chemical Physics

XXV. (SR-33) HIGH FIELD CONDUCTION AND CURRENT NOISE IMPLICATIONS OF MECHANISMS CONTRIBUTING TO BREAKDOWN IN THIN FILMS OF RbI (Jong Gil Lee)

ABSTRACT: This thesis is concerned mainly with high field electronic conduction through very thin $\mathrm{RbI}$ films sandwiched between two metal electrodes. Study also includes the implication of high field conduction mechanisms contributing to breakdown.

The structure control of the film was performed by the thin, high resistance top electrode which limits the flow of the stored capacitor charge to the high conduction region thereby limiting the rate of energy dissipation.

Evidence of space charge build-up is presented by memory in $I-V$ characteristics, decrease of onset time of self-healing breakdown in second pulse with delay time between the first and second applied pulses, and abrupt increase of conduction at the beginning of opposite polarity second pulse.

Current oscillation is also observed upon the application of rectangular pulse. Current is voltage and time dependent and current saturates in the long time range, $\sim 1$ second. There is threshold voltage at $3.9 \pm 0.1 \mathrm{eV}$ which coincides with electron-impace onset for excitation of intrinsic luminescence of thin film $\mathrm{RbI}$.

The following model is suggested. A few electrons at the bottom of the conduction band gain energy from the fleld, produce excitons near the anode. These excitons are ionized by electron tunneling. Holes 
drift toward the cathode, estab1ishing the virtual anode. A few holes survive recombination process to approach protuberances of the cathode, thereby increasing local field and field injection. The process continues with more electrons available for exciton generation near the anode. The threshold voltage is associated with the voltage necessary to maintain exciton generation.

The formation of $\mathrm{F}$ and $\mathrm{H}$ centers during electron-hole recombination process provides an additional mechanism. Ensuing $\mathrm{F}^{+}$(vacancies) centers near the anode and subsequent hopping motion of vacancies contributes the positive space charge formation near the cathode. H centers form immobile aggregates which stabilize $\mathrm{F}_{\text {and }} \mathrm{F}^{+}$centers.

(1) Submitted to the University of Notre Dame in Partial Fulfillment of the Requirements for the Degree of Doctor of Philosophy, January 1977

XXVI. (SR-37) COMPILATION OF RATE CONSTANTS FOR THE REACTIONS OF METAL IONS IN UNUSUAL VALENCY STATES ${ }^{1}$ (George V. Buxton ${ }^{\dagger}$ and Robin $M$. Sellers ${ }^{\dagger \dagger}$ ).

ABSTRACT: Kinetic data have been compiled for reactions of uncommon oxidation states of metals which are produced by radiolysis of aqueous solutions of metal ions. Most of the reaction rates are for transient. species, and the rates were determined by pulse radiolysis; some data were obtained by flash photolysis and gamma radiolysis. Metal ions from Groups IB, IIB, IIIA, IVA, VIB; VIIB, VIIIV, and the lanthanides are included in the compilation.

(1) Submitted for publication to the National Standard Reference Data Service, National Bureau of Standards

+ Cookridge Radiation Research Centre, Cookridge Hospital, Leeds Great Britian

t† Central Electricity Generating Borad, Berkeley Nuclear Laboratories, Berkeley, Glousestershire, Great Britian 
other researches in progress include the following:

XXVII. DISTRIBUTION OF DEPOSITED ENERGY AROUND HEAVY-ION TRACKS. (A. MOZumder)

The dipole oscillator distribution of water has now been obtained from the work of Zeiss et al. incorporating the effect of the liquid state from vacuum-UV reflection studies. The remaining problems which are now under study relate to the stopping and scattering of secondary electrons.

XXVII. EFFECT OF TRAPPING ON THE THERMALIZATION OF ELECTRONS IN HYDROCARBON LIQUIDS (A. Mozumder)

Earlier work by Sano and Mozumder connects mobility and free-ion yield in high-mobility liquids through a Fokker-Planck approach. The work is now being extended to low- and intermediate-mobility liquids by considering electron trapping before thermalization. At present we treat the case when the trapping cross section varies inversely as the energy. Trapping rates and thermalization distances consistent with free-ion yield and mobility will be evaluated.

XXIX. EFFECT OF FIELD-DEPENDENT MOBILITY ON ESCAPE PROBABILITY

(A. Mozumder)

Earlier work by the investigator has shown that the dependence of the electron mobility on field demands a smaller thermalization distance. in high-mobility (sublinear) hydrocarbon liquids than assumed before. The work is being continued to determine consistently: (1) the thermalization distribution for photoejected electrons from a metallic surface into a hydrocarbon liquid and (2) the density distribution of electrons in the steady-state in a coulomb field.

XXX KINETICS OF ELECTRON SCAVENGING REACTIONS (K. Funabashi) The time-dependent rate constant for electron scavenging was calculated by the model of continuous-time random walk (CTRW). The short-time magnitude of the rate constant is significantly different from the Smoluchowski transient. The Laplace-transform technique has 
been generalized to incorporate time-dependent rate contstants and the result of CTRW has been applied to the competitive kinetics of electron scavenging and ion recombination.

XXXI. SECOND-ORDER OPTICAL PROPERTIES OF SOLVATED ELECTRONS (Ian Carmichae1)

Evaluation of the second-order optical properties of solvated electrons has been attacked from two directions. The first appraoch analyses existing experimental absorption spectra in terms of dielectric dispersion relations using sum rule techniques coupled with moment theory. While no detailed model of the system need be invoked here, some features of the ground state must generally be assumed. The second appraoch involves direct computations from a range of specific models, from the polarized cavity to the semicontinuum level, again with the help of superconvergent sum rules, to eliminate the need for any knowledge of the excited states of the excess particle. Uncoupled calculations refined using the geometric approximation have been found adequate in most cases. In particular the frequency dependence of the polarizability has been evaluated, leading to estimates of static multipole polarizabilities and hyberpolarizabilities, scattering cross-sections, verdet coefficients and dispersion energies. The first approach indicates finite range binding potentials, implies transitions to an unbound continuum are responsible for first-order optical effects and shows negligible contributions from site averaging. By contrast, the latter treatment has previously assuined Coulomb traps, emphasized bound excited states and implicitly necessitated substantial configurational fluctuations to reproduce observed properties.

XXXII. MODEL MOLECULAR ORBITAL STUDIES OF THE CHEMISORPTION OF ATOMIC HYDROGEN AND OXYGEN ON ALUMINUM SURFACES (Harry F. Baney and Maurice E. Schwartz)

Interest in chemisorption and catalysis has grown rapidly in recent years, largely because of concern with environmental pollution and the "energy shortage". Advances in methodology has enhanced the study of these phenomena allowing both the experimentalist and theoretician to 
describe in greater detail the interaction between adsorbed atoms (molecules) and surfaces. We now have an active program to: study the gas-surface interaction by modern quantum mechanical techniques, many of which we have developed at Notre Dame. Our first studies are using a moleuclar orbital method to describe chemisorption and catalysis. The (100), (110), and (111) faces of aluminum unhealing with atomic oxygen and hydrogen are the model systems under study. Aluminum is a good first choice for study, since it is a common, real metal, and some of its forms (e.g., alumina) are powerful catalysts. Also, possible "d-orbital" participation, as postulated for transition metals, will be absent for A1, thus simplifying the problem. Clusters which have been studied include $\mathrm{Al}_{5} \mathrm{O}, \mathrm{Al}_{5} \mathrm{H}, \mathrm{Al}_{4} \mathrm{H}$ and $\mathrm{Al}_{4} \mathrm{O}$ ((100) surface), $\mathrm{AlH}, \mathrm{Al}_{3} \mathrm{H}, \mathrm{AlO}$, and $\mathrm{Al}_{3} \mathrm{O}$. (111) surface), and $\mathrm{Al}_{3} \mathrm{H}$, and $\mathrm{Al}_{3} \mathrm{O}$ ((110) surface). These studies were accomplished using the rigorous LCAO SCF MO valence-electron theory, with core effects represented by the model potential method first developed at Notre Dame by Schwartz and Switalski, and extended by Baney. By omitting explicit consideration of core electrons, this scheme can produce accurate electronic structure studies for rather large systems, such as those considered here.

Preliminary observations indicate that the most favorable site for chemisorption is an open site (above a hole or vacancy) as opposed to an overhead site (above an atom), for both atomic hydrogen and oxygen. Thus, an adequate description using MO theory requires a three-dimensional representation of the metal surface. Charge is transferred from the metal surface to both hydrogen and oxygen.

Often few comparisons can be made between experimental and theoretical MO descrjptions of chemisorption since identical systems are not studied by both experimentalist and theoretician. However, the exception to this problem is the area of metal atom matrix chemistry. Experimental results from the combination of the inorganic metal atom and an organic molecule utilizing cryogenic trapping techniques, matrix isolation infrared, laser Raman, ultraviolet-visible and ESR spectroscopy; and theoretical MO results can be used to describe the bonding in these organometallic complexes. This information can be used by the threoretical surface chemist to evaluate the MO approach if it is assumed that the one metal atom represents an active site in chemisorption an idea repeatedly advanced by experimental chemists on experimental grounds. Thus, the 
understanding of metal atom matrix chemistry can be utilized in understanding both heterogeneous and homogeneous catalysis, and this information has possible applications for the synthesis of organo-metallic compounds with specific catalytic properties. Aside from our earlier described cluster work, our possible study of metal atom matrix complexes include $\mathrm{AlC}_{2} \mathrm{H}_{4}, \mathrm{LiC}_{2} \mathrm{H}_{2}$ and $\mathrm{LiC}_{2} \mathrm{H}_{4} \cdot$ Results for $\mathrm{AlC}_{2} \mathrm{H}_{4}$, which has been prepared in the laboratory, indicate that the complex is stable by $1.5 \mathrm{kcal}$. The LiC ${ }_{2} \mathrm{H}_{2}$ and $\mathrm{LiC}_{2} \mathrm{H}_{4}$ complexes, also experimentally known, are presently under study.

XXXIII. CALCULATION OF SUM RULE MOMENTS FOR $\mathrm{H}_{2}$ O (D.M. Chipman)

Accurate Hartree-Fock and valence bond calculations have been preformed on the sum rule moments $s_{k}(F)$ of the electric dipole photoabsorption cross section of $\mathrm{H}_{2} \mathrm{O}$, with $\mathrm{k}$ ranging from -1 to +2 . Our values averaged over all molecular orientations are in good agreement with experiment, the discrepancies being less than 10\%. The calculations also provide values for the experimentally inaccessible $x-, y-$ and $z$ - components of the sum rule moments.

The sum rule moments are used in conjunction with moinent theory to calculate for water vapor the refractivity, the Faraday rotation, the cross section and depolarization ratio for combined Raman plus Rayleigh scattering, the van der Waads dispersion energy, and parameters in the Bethe-Born theory for energy loss by fast charged particles. Agreement with experiment is moderately good where comparisons are possible. This work represents the first determination by any method of the dependence of the $\mathrm{H}_{2} \mathrm{O}$ dispersion energy on molecular orientation.

XXXIV. EARLY EVENTS IN PULSE-IRRADIATED POLAR LIQUIDS (D. Razem and

W.H. Hami11)

Rate constants for ten simple olefins reacting with $e_{s}^{-}$in ethanol are in the range $10^{6}-10^{7} \mathrm{M}^{-1} \mathrm{~S}^{-1}$. They do not react measurably with dry electrons, e, supporting the hypothesis that $e_{s}^{-}$is $\mathrm{C}_{2} \mathrm{H}_{5} \mathrm{OH}^{-}$which transfers $H$ to olefins.

Scavenging $\mathrm{e}^{-}$by $\mathrm{Cd}^{2+}$ was previously reported to be $\sim 40 \%$ more efficient in $\mathrm{D}_{2} \mathrm{O}$ than in $\mathrm{H}_{2} \mathrm{O}$. For $\mathrm{G} / \mathrm{G}^{\circ}=0.37, \mathrm{C}_{37}$ (dimethyl-sulfoxide) 
is $~ 2.3 \mathrm{M}$ in $\mathrm{C}_{2} \mathrm{H}_{5} \mathrm{OH}$ and $\sim 1.3 \mathrm{M}$ in $\mathrm{C}_{2} \mathrm{H}_{5} \mathrm{OD} ; \mathrm{C}_{37}$ (allyl alcohol) is $\sim 0.74 \mathrm{M}$ in $\mathrm{C}_{2} \mathrm{H}_{5} \mathrm{OH}$ and $\sim 0.43 \mathrm{M}$ in $\mathrm{C}_{2} \mathrm{H}_{5} \mathrm{OD}$, both at $300 \mathrm{~K}$. At $150 \mathrm{~K}$ in $\mathrm{C}_{2} \mathrm{H}_{5} \mathrm{OH}$, $\mathrm{C}_{37}$ (allyl alcohol) is $\sim 0.15 \mathrm{M}$. The isotope effect is attributed to localization of $\mathrm{e}^{-}$by molecular negative ion formation with prompt transfer of $O H$ or OD vibrational energy to the lattice. This correlates with decreasing $\mathrm{C}_{37}$ (DMSO) for $\mathrm{ROH}$ in the series $\mathrm{R}=\mathrm{H}, \mathrm{CH}_{3}, \mathrm{C}_{2} \mathrm{H}_{5}, \mathrm{C}_{3} \mathrm{H}_{7}$ with $\mathrm{C}_{37}=\sim 12,6,2$ and $1 \mathrm{M}$ respectively, the "oxygen concentration" effect of Hunt and Chase. In their linear plot $C_{37}$ (acetone) vs. [0] solvent, the point for water requires $[0]_{\mathrm{H}_{2} \mathrm{O}}=55 \mathrm{M}$. . This correlates with excitation of bending, but not stretching, vibrations.

XXXV. RADIATION CHEMICAL STUDIES OF REACTIONS OF SORGANIC COMPOUNDS (V. Madhavan, Hedva Levanon and P. Neta)

Following up a recent kinetic study of $\mathrm{SO}_{1}^{-}$reactions, we have ivestigated the mechanism of reaction of this radical by analyzing some of the products. Oxidative determination of bromoaromatic compounds by $\mathrm{SO}_{4}^{-}$was studied in comparison with the similar reaction by $\mathrm{OH}$. The effects of substitients on the $\mathrm{Br}^{-}$yield was found to be markedly different for the two reactions, indicating different mechanisms. The reaction of $\mathrm{so}_{4}^{-}$with aromatic and aliphatic carboxylic acids leads to a considerable extent of decarboxylation while the reaction of $\mathrm{OH}$ does not. An extreme example is phthalic acid, where decarboxylation by $\mathrm{SO}_{4}$ was found to be $100 \%$ efficient. Decarboxylation of benzoic and terephthalic acid was only about half at efficient. Decarboxylation of acetic and malonic acid by $\mathrm{SO}_{4}^{-}$was also $\sim 50 \%$ efficient, the rest presumably resulting in $\mathrm{H}$ abstraction. The yield of $\mathrm{CO}_{2}$ from glycine and alamine was found to be very high indicating a chain reaction.

XXXVI. THE REACTIONS OF THE PHOSPHATE AND SULFATE RADICALS WITH INORGANIC COMPOUNDS (P. Marathamuthu and P. Neta)

In continuation of our earlier investigation of the reactions of phosphate and sulfate radicals, we have carried out $\gamma$-and pulse radiolysis experiments with peroxodiphosphate (PDP) and peroxodisulfate (PDS) in the presence of a variety of inorganic compounds. It is found that in the presence of phosphite, hypophosphite and hydrogen peroxide, both PDP and PDS undergo radiolytic chain reactions. With most of the compounds 
studied the rate constants for the reaction of $\mathrm{H}_{2} \mathrm{PO}_{4}$ are similar to those of $\mathrm{SO}_{4}^{-}$while the rate constant of $\mathrm{HPO}_{4}^{-}$and $\mathrm{PO}_{4}^{-2}$ are lower by a factor of ten. Hydroxylamine and hydrazine were found to be more reactive in neutral than in acid solution inspite of the slow reactivity of $\mathrm{PO}_{4}^{2-}$ as compared with $\mathrm{H}_{2} \mathrm{PO}_{4}$. In the case of halide ions, the reactivity of $\mathrm{H}_{2} \mathrm{PO}_{4}$ decreases in the order $\mathrm{I}^{-}>\mathrm{Br}^{-}>\mathrm{Cl}^{-}$. The rate of reaction with $\mathrm{Cl}^{-}$is higher for $\mathrm{SO}_{4}^{-}$than $\mathrm{H}_{2} \mathrm{PO}_{4}$ by a factor of 140 . The rate with $\mathrm{Br}^{-}$ also decreases in the order $\mathrm{SO}_{4}^{-}>\mathrm{H}_{2} \mathrm{PO}_{4}>\mathrm{HPO}_{4}^{-}$. The results suggest that $\mathrm{SO}_{4}^{-}$is a stronger oxidant than $\mathrm{H}_{2} \mathrm{PO}_{4}^{-}$.

XXXVII. PULSE RADIOLYSIS STUDIES OF ANTIOXIDANTS IN FATTY ACID SOAP AGGREGATES

(Larry K. Patterson)

The antioxidant properties of the tocopherols are well known. However, time resolved studies of radical processes related to their anti-oxidant character have been limited by solubility considerations. Using sodium linoleate micelles in which $\alpha$-tocopherol has some solubility, pulse radiolysis studies are being carried out to determine the kinetics of interaction between this molecule and various fatty acid radicals. In both $\mathrm{N}_{2} \mathrm{O}$ and air saturated solutions, OH attack on the aggregate molecules is followed by appearance of a transient associated with solubilized $\alpha$-tocopherol. The absorption spectrum, with an assymetric band at $440 \mathrm{~nm}$ and strong absorption below $350 \mathrm{~nm}$ resembles closely tht observed for duroquinone anion radical. This behavior suggests donation of an $\mathrm{H}$-atom from the phenolic group to hydrocarbon or peroxide radical sites. Similar processes at allylic radical sites may serve as termination steps in oxidative chain mechanisms. Within the concentration range of one to ten times the cmc for linoleate micelles, the period of growth for this transient in aerated systems is about $400 \mu \mathrm{sec}$ through the yield varies for a constant concentration of $\alpha$-tocopherol. Such kinetics Indicate that the antioxidant cannot migrate among micelles within the fatty acid radical lifetime and only reacts if a radical appears in the micelle where it resides. 
XXXVII. SPECTROPHOTOMETRIC PULSE RADIOLYTIC STUDY OF THE RADICALS PRODUCED

BY REDUCTION OF CIS- AND TRANS-AZOBENZENE (P. Neta and Haim Levanon)

The radicals produced by reduction of cis- and trans-azobenzene in tetrahydrofuran and in aqueous solutions were studied spectrophotometrically. The transient spectra observed in all solutions were identical for both isomers. The spectrum in aqueous solutions consisted of two main absorption maxima which were dependent upon the pH. At $\mathrm{pH} \cdot 14$ the peaks were at 380 and $560 \mathrm{~nm}$ with extinction coefficients of $2.1 \times 10^{4}$ and $5.5 \times 10^{3} \mathrm{M}^{-1} \mathrm{an}^{-1}$ respectively. In neutral solution the maxima were blue shifted to 345 and $540 \mathrm{~nm}$. However, at $\mathrm{pH} 1$ only a maximum at $590 \mathrm{~nm}$ was observed while an apparent absorption below $350 \mathrm{~nm}$ was marked by the bleaching of the parent compound. From the spectral changes pK values of 2.9 and 13.7 were determined. Pulse conductometric measurements showed that the equilibria can be represented by $(\phi N H N H \phi)^{\circ+} \rightleftharpoons \phi N H \dot{N} \phi \rightleftharpoons(\phi N N \phi)^{\bullet-}$. The spectrum of the anion, radical in THF has a maximum at, $430 \mathrm{~nm}$ with a weak shoulder extending to $\sim 600 \mathrm{~nm}$. The identity of the spectra observed with the two isomers suggests that one-electron reduction of azobenzene results in a considerable saturation of the $N=N$ bond to allow rapid rotation around it.

XXXIX. CORRELATION OF SINGLET ENERGIES OF AROMATIC HYDROCARBONS WITH THE RATES OF PROTONATION OF THEIR ANION RADICALS (Haim Levanon, P. Neta and A.M. Trozzolo)

The reaction of solvated electrons with an aromatic hydrocarbon in alcoholic solution produces the anion radical. This radical protonates according to $\mathrm{Ar}^{\bullet}+\mathrm{ROH} \rightarrow \dot{\mathrm{ArH}}+\mathrm{RO}$. Protonation rate constants for a series of compounds in various alcohols were determined by kinetic spectrophotometric pulse radiolysis. In each solvent the protonation rate constants were found to correlate with the $S_{0} \rightarrow S_{1}$ transition energies of the aromatic hydrocarbon. As the energy gap, $\Delta E$, between the ground and the first excited singlet increases the rate of proton transfer becomes faster. The rate constants in 2-propano1, for example, vary from $4 \times 10^{2} \mathrm{~s}^{-1}$ for perylene $\left(\Delta \mathrm{E}=23,000 \mathrm{~cm}^{-1}\right)$ to $5.7 \times 10^{5} \mathrm{~s}^{-1}$ for naphthalene $\left(\Delta \mathrm{E}=32,200 \mathrm{~cm}^{-1}\right)$. A corollary linear correlation is also obtained between the rate constants and the ionization potentials. 
Since LCAO calculations showed that the sum of ionization potential and electron affinity for a series of aromatic hydrocarbons is constant the rates of protonation allow the estimation of electron affinity.

\section{THE ASSOCIATION RATE OF SODIUM LAURYLSULFATE MICELLE-MONOMER}

EQUILIBRIUM (T. Chen and J.K. Thomas)

Micelles are dynamic aggregates. The rate of monomer dissociating from micelle has been intensively studied. However, the rate of monomer associating with micelle has received little attention. In this study, both benzoquinone $(B Q)$ and duroquinone $(D Q)$ were used as electron acceptors. $B Q$ can pull out on $e^{-}$from NaLS radica1, but $D Q$ cannot when solubilized in NaLS micellar core, indicating that $B Q$ is in the water phase. Taking advantage of the defference between $e^{-}$transfer and association rates, the association rate constants of NaLS micelle has been determined $\sim 1.6 \mathrm{x}$ $10^{8} \mathrm{M}^{-1} \mathrm{~s}^{-1}$.

\section{TRANSFER OF AN ORGANIC MOLECULE BETWEEN MICELLES IN AN AQUEOUS}

ENVIRONMENT (F. Greiser and J.K. Thomas)

An organic probe (P) solubilized in a micellar solution is in equilibrium with the micelle (M) and the aqueous environment. By exciting the probe (which excites predominately in the micelle's hydrocarbon phase) and adding a quencher molecule (Q) which only exists in the aqueous medium, movement of $\mathrm{P}$ between micelles in solution can be studied.. A kinetic scheme is represented by the equations,

$$
\begin{aligned}
& \mathrm{MP}^{*} \underset{\mathrm{k}_{-1}}{\stackrel{\mathrm{k}_{1}}{\rightleftharpoons}} \mathrm{M}+\mathrm{P} * \\
& \mathrm{P}^{*}+\mathrm{Q} \stackrel{\mathrm{k}_{2}}{\longrightarrow} \text { Quenching } \\
& \mathrm{P}^{*} \stackrel{\mathrm{k}_{3}}{\longrightarrow} \mathrm{hv}+\mathrm{P} \\
& \mathrm{MP} * \stackrel{\mathrm{k}_{4}}{\longrightarrow} \mathrm{hv}+\mathrm{MP}
\end{aligned}
$$

With suitable approximations it can be shown that 


$$
\mathrm{k}_{\mathrm{obs}}=\mathrm{k}_{1}+\mathrm{k}_{4}-\frac{\mathrm{k}_{1} \mathrm{k}_{-1}^{[M]}}{\mathrm{k}_{2}[\mathrm{Q}]+\mathrm{k}_{3}+\mathrm{k}_{1}[\mathrm{M}]}
$$

Therefore if the quencher concentration becomes larger the $k_{\text {obs }}$ will approach a limiting value $=k_{1}+k_{4}$.

Experimental results show that in $0.04 \mathrm{M}$ CTAB, using 1-bromonaph thalene as the probe, the plateau value is reached at $\sim 2 \times 10^{-3} \mathrm{M}$ quencher concentration $\left(\mathrm{Cu}^{2+}\right)$. This gives on exit rate constant $\left(\mathrm{k}_{1}\right)$ of $7.8 \mathrm{x}$ $10^{2} \mathrm{sec}^{-1}$. In $0.04 \mathrm{M}$ NaLS the plateau value is reached at $\sim 8 \times 10^{-3} \mathrm{M}$ of quencher (either $\mathrm{I}^{-}$or $\mathrm{CH}=\mathrm{C}\left(\mathrm{CH}_{3}\right) \mathrm{COO}^{-}$). For this system on exit rate constant of $\sim 2 \times 10^{2} \mathrm{sec}^{-1}$ is obtained. These results may be indicative of the position of the probe molecule within the micelle.

XLII. IN SITU-PHOTOLYSIS-ESR STUDY OF SOME REACTIONS OF PHOSPHATE RADICALS

(H. Taniguchi and P. Maruthamuthu)

Free radical intermediates formed in the reaction of phosphate radicals $\left(\mathrm{PO}_{4}^{2-}\right.$ or its protonated species, $\mathrm{HPO}_{4}^{-}$and $\mathrm{H}_{2} \mathrm{PO}_{4}$ ) with a number of fundamental organic and inorganic compounds have been studied using in situ photolysis-steady state ESR method. Phosphate radical was generated effectively by the photolysis of peroxodiphosphate $\left(\mathrm{P}_{2} \mathrm{O}_{8}^{4-}\right)$ in aqueous solutions.

Though phosphate radical itself could not be detected directly, ESR spectra of phosphate radical adducts to fumaric and maleic acids and nitromethane aci-anion were observed successfully and $\mathrm{pK}_{\mathrm{a}}$ value for the proton dissociation in phosphate group of adduct radical, - $\mathrm{OOC} \mathrm{CH}\left(\mathrm{OPO}_{3} \mathrm{H}^{-}\right) \dot{\mathrm{C}} \mathrm{H} \mathrm{COO}^{-}$, has been determined to be 6.7 .

The reactions of phosphate radicals are very similar to those of $\mathrm{so}_{4}^{-}$, i.e., they give raise to similar adduct radicals with unsaturated compounds, and inorganic radicals such as $\dot{\mathrm{CO}}_{3}^{-}$from $\mathrm{HCO}_{3}^{-}, \dot{\mathrm{N}}_{2} \mathrm{H}_{4}^{+}$from $\mathrm{N}_{2} \mathrm{H}_{5}^{+}$, etc. However there are some differences towards saturated carboxylic acids. For example, $\alpha$-carbon radicals produced by hydrogen abstraction with phosphate radicals were mainly detected from mono- and di-carboxylic acids in neutral aqueous solutions, while the resultant radicals by decarboxylation were observed in $\mathrm{SO}_{4}^{-}$system. Clearly direct oxidation is not the predominant one in the reaction of phosphate radical $\left(\mathrm{HPO}_{4}^{-}\right)$with the saturated carboxylic acids. 
XLIII. PHOTOCHEMISTRY OF SYDNONES (A. Sarpotdar and A.M. Trozzolo)

In order to gain more insight into the photochemical behavior of sydnones I and II, their thermal behavior was studied. The thermolysis of I in m-xylene gives II a product:

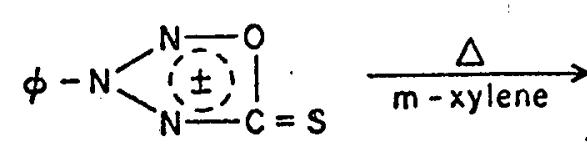

I

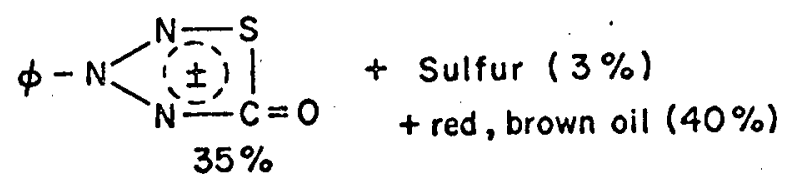

II

It is suggested that the rearrangement may proceed through an intermediate such as III (see previous Quaterly Report)

$$
\begin{aligned}
& \phi-N=\mathbb{N}=N-C_{S}^{O^{-}} \\
& \phi-N=\mathbb{N}=N-C_{S^{-}}^{0}
\end{aligned}
$$

III

which is probably involved in the photochemical rearrangements of $I$ and II.

XLIV. DIFFERENTRATION OF TRIPLET STATE AND BIRADICAL REACTIONS (R.D. Small and J.C. Scaiano)

Where a photoreaction involves more than one potentially reactive intermediate it is often difficult to determine which species is responsible for a given reaction. The photochemistry of valerophenone in the presence of oxygen illustrates this behaviour;

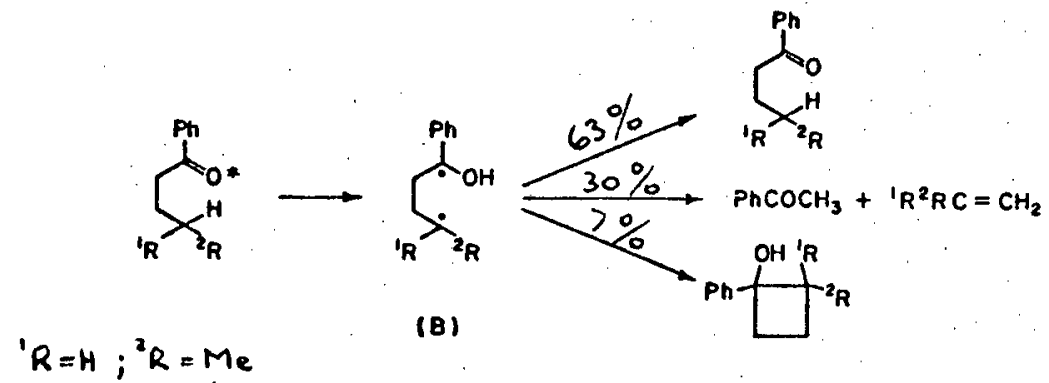

where the asterisk denotes the triplet state and the yields correspond to benzene as solvent. Oxygen has no apparent effect on the yield of acetophenone, the main product. This has been frequently attributed to 
inefficient quenching of the triplet state. We have been able to establish that oxygen does indeed quench the triplets as could be expected, but it also interacts with $B$ increasing the fraction of these biradicals which give acetophenone from $30 \%$ to $80-90 \%$ via the formation of an intermediate complex. In the particular case of valerophenone the triplet and biradical lifetimes are such that the two effects tend to compensate almost quantitatively. A number of techniques have been developed which allow the differentiation of triplet state and biradical processes, and include 'tuning' the triplet lifetime to a desired value using suitable energy acceptors, use of strong hydrogen bonding substrates or phosphorous compounds to 'fix' the biradical behavior (make it independent of oxygen), viscosity effects, etc. These techniques are of a rather general nature and the valerophenone-oxygen system simply provides an excellent example where these methods can be tested.

XLV. THE PHOTOENOLIZATION OF AROMATIC KETONES (R.D. Small and J.C. Scaiano) Ortho alkyl substituted acetophnones and benzophenones undergo intramolecular hydrogen abstraction under UV irradiation, in a process which resembles the Norrish Type II reaction but effectively results in the photoenolization of the ketone, i.e.
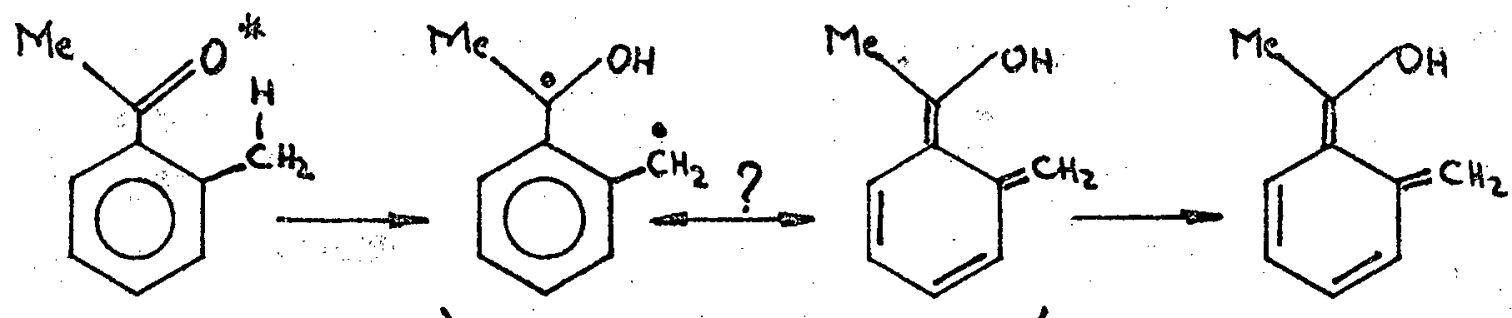

$$
\begin{aligned}
& \text { Triplet biradical } \\
& \text { or triplet enol }
\end{aligned}
$$

The question as to whether the transient species (see bracket) should be regarded as a biradical or the triplet state of the enol has been in the literature for a number of years, and remains without a conclusive answer. We have been able to show that the 'transient' reacts with bipyridilium dications in an electron transfer process in much the same way as open chain 1,4-ketyl alkyl biradicals do. The transient species has a lifetime in the neighborhood of $0.3 \mu \mathrm{s}$ in methanol and for the electron transfer to paraquat dications a rate 
constant of $4.5 \times 10^{9} \mathrm{M}^{-1} \mathrm{~s}^{-1}$. These characteristics as well as the efficient scavenging by oxygen demonstrate that the transient mentioned above resembles in its kinetic behavior properties which are typical of free radical centers. The effect of substitution, solvent and temperature on the reaction are currently being examined.

XLVI. PHOTOCHEMICAL REACTIONS OF CU(II) COORDINATION COMPOUNDS WITH MACROCYCLIC LIGANDS (G. Ferraudi)

Irradiation of $\mathrm{Cu}[13-\mathrm{A}+\mathrm{H}]$ and $\mathrm{Ni}[13-\mathrm{A}+\mathrm{H}]^{2+}$ in the region of the charge transfer bands (200-400 nm) produced redox reactions and ligand hydrolisis. Products were isolated and characterized as a trienetetraaza and a monoenetetraaza macrocyclic complexes. The ligand oxidized product was also generated in solutions of these complexes by $\gamma$-irradiation. Quantum yields were measured at different wavelengths and under various conditions for both reaction modes. Such results have shown that the redox pathway is more important than the solvolytic degradation in contrast with the observed behaviour of $\mathrm{Cu}\left[[14] \text { diene } \mathrm{N}_{4}\right]^{2+}$. Experiments are presently being performed in order to gain some insignt in the nature of the intermediates in these processes.

XLVII. STUDIES OF NI(III) MACROCYCLIC LIGAND COMPLEXES (Larry K. Patterson and G.J. Ferraudi)

Investigations of $\mathrm{OH}$ attack on $\mathrm{Ni}$ (III) complexes have been extended to several macrocyclic ligand systems:

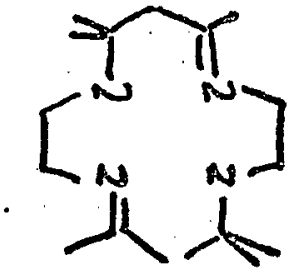

[[14]-diene $\mathrm{N}_{4}$

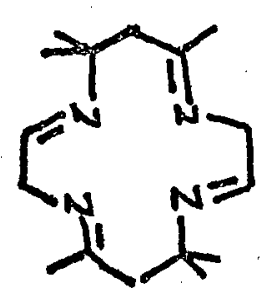

$\left[[14]-1,4,8,11-\right.$ tetraene $\left.\mathrm{N}_{4}\right]$

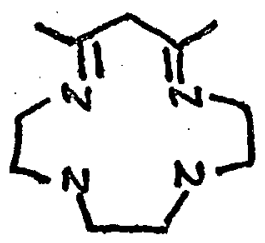

$[[13]-\mathrm{AtH}]$

The $\mathrm{OH}$ is produced radiolytically and studies carried out by optical pulse radiolysis methods. In most cases, transients generated in this fashion appear to result from oxidation of the central metal ion. Lifetimes of these transient specles range from milliseconds to tens of seconds and may be altered by both pit as well as added electrolyte. 
The appearance of strong $d-d$ transition bands in some cases suggests marked ligand distortion associated with the with central ion oxidation. In studies of the AtH complex, an acid-base equilibrium has been observed and exhibits a much lower $\mathrm{pK}$ value than that for the corresponding $\mathrm{Ni}$ (III) system. Electron transfer reactions involving other metal complexes and pulse polarographic experiments on these systems have shown that the Ni(III) macrocyclics behave as powerful oxidants.

XLVIII. PHOTOCHEMISTRY OF ORGANOMETRALLIC COMPOUNDS WITH METAL-METAL BONDS

(S. Madhavan and J. A. Labinger)

Diamanganese decacarbony 1 undergoes a photo-induced reaction with benzaldehyde and several other aldehydes, to generate a transient, strongly colored (orange or red-orange) intermediate which can be observed by either visible or infrared spectral changes. This intermediate disappears, apparently by a second-order reaction, with a halftime of several minutes. For benzaldehyde a stable product is also produced; this has been partially characterized as a CO-free Mn(II) complex of organic ligands derived from benzaldehyde. Attempts to characterize this product by means of X-ray crystallographic analysis as well as the nature of the intermediate species are in progress.

\section{IL. TRIPLET STATE FORMATION OF IODO-AROMATIC COMPOUNDS (F. Grieser and J.K. Thomas)}

Compounds such as iodo-naphthalene and iodo-biphenyl, unlike their other halo homologues, do not show any phosphorescence when excited at room temperature, yet both have been reported to phosphorescence when excited at $77^{\circ} \mathrm{K}$. Results to date suggest that at room temperature, the triplet state dissociates into an iodine atom and aromatic moiety. The triplet of 1iodonaphthalene, produced by a triplet-triplet transfer process in radiolytically excited toluene, is a classic example of a unimolecular

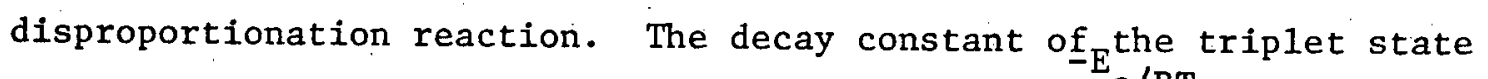
can be expressed by the Arrhenius equation $12=\mathrm{Ae} a / R T$, where $A$ is experimentally found to be $10^{13.0} \mathrm{sec}^{-1}$, and $\mathrm{E}_{\mathrm{a}}=7.0 \mathrm{kcal} / \mathrm{mole}$ over the temperature range $-20^{\circ} \mathrm{C}$ to $-70^{\circ} \mathrm{C}$. The room temperature behaviour of the triplet iodo-aromatics may make them a useful probe for studying micellar systems. 
Laser photolysis experiments on such systems will be conducted in the near future.

\section{LUMTNESCENCE OF ALKANE SOLIDS DOPED WITH AROMATICS UNDER VACUUM UV EXCITATION (Robert G. Hayes) \\ We are interested in the formation of mobile excited states in} condensed phases which arise from primary excitations in the vacuum ultraviolet (VUV). In particular, we are interested in mobile excitations which eventuate from excited ionic states of the system. We have, as a beginning, interested ourselves in hydrocarbon solids in the $\mathrm{C}_{5}-\mathrm{C}_{8}$ range because of direct evidence from electron impact (1) and indirect evidence from radiation chemical studies (2-5) of the formation of mobile excitations. A simple apparatus to observe the fluorescence of pure or doped hydrocarbon films at $77^{\circ} \mathrm{K}$ under VUV excitation, has been assembled. This apparatus consists of a small stainless steel chamber, capable of maintaining pressures in the high $10^{-9}$ range under favorable conditions when pumped by a 20 $\ell / \sec$ ion pump. It is provided with a stainless cold finger which is seen by a sapphire view port and by the excitation beam, brought into the chamber through an in-line value. During the week of March 14-18 this chamber was mounted at the exit beam of a $1 / 2 \mathrm{~m}$ Seya-Namaioka monochromator installed on the electron storage ring Tantalus $I$ at the University of Wisconsin Physical Science Lab., Stoughton, Wisconsin. We were interested in seeing how the system functioned with a view to deciding on an improved version of the apparatus and also in doing some preliminary experiments to see what sort of luminescence we could expect and, thus, what was required by way of detection. It was found, perhaps unsurprisingly, that more efficient pumping would be a big help and that, in particular, a differential pumping stage between the system and the monochromator (which is capable of only about $2 \times 10^{-7}$ torr) would be most useful. The detection system also needs improvements, of which the salient one is a gating system to discriminate against the high level of stray light in the visible which passes through the monochromator.

Films of cyclohexane doped with $2 \%$ toluene were studied under the optimum conditions at our disposal. Our detection signal to noise ratio was not high enough to allow us to use the monochromator so we studied total visible luminescence. The response of the system was calibrated in a 
separate experiment using a film or sodium salicylate as a converter. We found a maximum luminescence quantum yield in the visible of somewhat less than one percent in this system, peaking at an excitation energy of some $11 \mathrm{eV}$.

It seems clear that the modest improvement in the experiment will allow us to get a clear idea of the efficiency of energy transfer from excited valence states in various alkanes and of the distribution of this efficiency in excitation energy.

LI. ELECTRON REACTIONS IN THE GAS PHASE (H. Shimamori and Richard W. Fessenden)

E1ectron attachment in $\mathrm{N}_{2} \mathrm{O}-\mathrm{CO}_{2}$ mixtures has been studied by microwave conductivity method. In $\mathrm{CO}_{2}$-rich mixtures the dependence of electron attachment rates on $\mathrm{CO}_{2}$ pressure is independent of the composition of mixtures. The main features of the results can be explained by the following two-state three-body process,

$$
\begin{aligned}
& \mathrm{e}+\mathrm{H}_{2} \mathrm{O} \stackrel{\mathrm{k}_{1}}{\longrightarrow} \mathrm{N}_{2} \mathrm{O}^{-*} \\
& \mathrm{~N}_{2} \mathrm{O}^{-*}+\mathrm{CO}_{2} \stackrel{\mathrm{k}_{3}}{\longrightarrow} \text { stable ion. }
\end{aligned}
$$

$k_{1}$ and $k_{1} k_{3} / k_{2}$ (three-body rate constant for $\mathrm{CO}_{2}$ as a third body) are found to be $3.3 \times 10^{-13} \mathrm{~cm}^{3} / \mathrm{molecule}^{\mathrm{sec}}$ and $2 \times 10^{-31} \mathrm{~cm}^{6} / \mathrm{molecule} \mathrm{sec}$, respectively. In $\mathrm{N}_{2} \mathrm{O}$-rich mixtures the addition of a small amount of $\mathrm{CO}_{2}$ gives rise to a remarkable increase of the attachment rates. The results suggest the presence of some complicated mechanism such as an over-all four-body process. For a thorough understanding of the mechanism further experiments with $\mathrm{N}_{2} \mathrm{O}-\mathrm{CO}_{2}$ and $\mathrm{N}_{2}$ O-hydrocarbon mixtures are in progress.

LII. LOW-ENERGY ELECTRON RESONANCES IN ORGANIC THIN FILMS (J.H. Jischke and W.H. Hamil1)

Transmission of vacuum-injected electrons by thin molecular films is being used to detect compound negative Ion resonances and bulk electron affinities $K$ for several olefins. The zero of energy is established from triplet 
and singlet states, when these are known. The lowest resonances are substantially the same as in the low-pressure gas, $\sim 2 \mathrm{eV}$, and are therefore molecular rather than solid state effects. Within $\pm 0.1 \mathrm{eV}$, $K$ is $\sim 0.3 \mathrm{eV}$, excepting ethylene for which it is $\sim 0 \mathrm{eV}$.

LIII. HIGH-FIELD CONDUCTION IN THIN-FILM RBI AND KI (M. Pisanias and W.H. Hami11)

Capacitors $\sim 10^{-5} \mathrm{~cm}$ thick of the type A1-RbI-A1 become conducting ( $10^{-2} \mathrm{~A} \mathrm{~cm}^{-2}$ ) at $>10^{5} \mathrm{~V} / \mathrm{cm}$ due to accumulation of drifted positive ionic defects at the cathode, $\sim 10^{13} \mathrm{~cm}^{-2}$ within $\sim 50 \AA$, by high-field injection. Deposition of $\sim 10^{13} \mathrm{~cm}^{-2} \mathrm{Rb}$ atoms on the $\mathrm{RbI}$ film to generate $F$ centers greatly increases conductivity indicating involvement of anion vacancies which are normally present in the defect film. Two electron injection mechanisms with thresholds at $\sim 4$ and $2.5 \mathrm{~V}$ are raised by $\sim 0.6 \mathrm{~V}$ for gold electrodes due to increased work function. Between these thresholds the increasing $I_{e}(t)$ for electrons depends on $\mathrm{V}$ and $\mathrm{T}$ with invariant shape and $\mathrm{E}_{\text {act }}=0.9 \mathrm{eV}$, comparable to the known value for ionic conductivity. For large $t, I_{e}(V)$. approaches constancy at all $\mathrm{T}$. At $₹ 2 \mathrm{~V}$ the decreasing $I_{i}(t)$ for ionic defects also depends on $\mathrm{V}$ and $\mathrm{T}$ with invariant shape and $\mathrm{E}_{\text {act }}=0.4 \mathrm{eV}$, not yet understood. Switching from $2 \mathrm{~V}$ to $2.5 \mathrm{~V}$, e.g., gives an enhanced $I_{e}(t)$. Switching from $2 \mathrm{~V}$ to 0 gives $-\mathrm{I}_{i}(t)$ from depolarization.

\section{RESONANT RAMAN STUDIES OF CRYSTALLINE PYRAZINE WITH TUNABLE}

UV LASERS - A DETAILED VIBRONIC ANALYSIS AND A TEST OF RAMAN

THEORIES (H.K. Hong and C.W. Jacobsen)

Recently we proposed a theory of resonant Raman for the strong vibronic coupling limit. Experimentally, we also observed resonant Raman enhancement of $\nu_{6 a}$ and $\nu_{10 a}$ in pyrazine by a factor of $10^{6}$, using tunable uv lasers. Of particular interest is the interactions between the first and second excited states of pyrazine. These couplings are responsible for the enhancement of Raman intensity. In the particular example of pyrazine, the experiments show that a coupling constant as large as $1264.5 \mathrm{~cm}^{-1}$ mixes the $B_{3 u}$ state with the $B_{2 u}$ state, with the following consequences for the lowest excited state of pyrazine: (1) the 
potential becomes anharmonic, (2) the frequency of $\nu_{10 a}$ is reduced almost by a half and (3) a large resonant enhancement effect for Raman. Quantitative information can therefore be obtained when theory and experiment are combined.

LV. POLARIZED TWO-PHOTON SPECTRA OF NAPHTHALENE IN DURENE WITH ONE AND TWO DYE LASER BEAMS (N. Mikami and H. K. Hong)

Polarized two-photon absorption spectra of naphthalene in durene are studied in detail. One beam experiments in which two photons of the same energy and polarization are absorbed yield information on the diagonal elements of the two-photon absorption tensor. Two beams experiments in which two photons of different energies and polarizations are absorbed yield information on the off-diagonal elements of the two-photon absorption tensor. Both experiments were done on naphthalene-doped durene single crystals. The symmetry and mode characters of the vibronically-induced two-photon spectra can be easily assigned and interpreted with the aid of the polarization data.

LVI. ANGULAR ENTROPY IN DIFFERENTIAL ELASTIC CROSS SECTIONS (John Bentley)

The information theory approach of Faist, Levine and Bernstein is applied to angular differential elastic cross sections. A "sophisticated prior" distribution function is used, in which the long-range attractive potential is approximated by a term $V(r)=-C_{s} r^{-s}$. With $s$ determined from the slope of the data as the scattering angle goes to zero, $\mathrm{C}_{\mathrm{s}}$ is varied and the angular entropy $\Delta \mathrm{S}[\mathrm{w}]$ is calculated. The dependence of $\Delta S[w]$ on $C_{S}$ is small for the cases studied to date, suggesting that $\Delta \mathrm{S}[\mathrm{w}]$ is primarily characteristic of the potential well. 